\title{
Improvement of Yields in Chickpea (Cicer Arietinum. L): Genetic Study of Heterosis in Hybrids Derived from Desi x Kabuli and Kabuli x Kabuli Crosses
}

\author{
Bayahi $\mathrm{K}^{1,2^{*}}$ and Rezgui $\mathrm{S}^{2}$ \\ ${ }^{1}$ Department of Biological Sciences Genetics and Molecular Biology, Faculty of sciences of Tunis, University of Tunis el Manar, \\ Tunisia \\ ${ }^{2}$ Department of $A B V$, National Agronomical Institute of Tunisia, Tunisia
}

${ }^{*}$ Corresponding author: Bayahi K, Department of Biological Sciences Genetics and Molecular Biology, Faculty of sciences of Tunis (FST), Campus University 2092-El Manar Tunis, University of Tunis el Manar, Tunisia, Tel: +21625815 199, E-mail: kaouthar-bayahi@hotmail.com

Citation: Bayahi K, Rezgui S (2018) Improvement of Yields in Chickpea (Cicer Arietinum. L): Genetic Study of Heterosis in Hybrids Derived from Desi X Kabuli and Kabuli X Kabuli Crosses. J Adv Plant Sci 1: 101

Article history: Received: 26 February 2018, Accepted: 25 April 2018, Published: 26 April 2018

\begin{abstract}
To improve yield and agro morphological characters and study the heterosis expressed in Desi x Kabuli and Kabuli x Kabuli crosses in chickpea, four crosses between exotic cultivars of Desi and Kabuli type and two Tunisian kabuli varieties have been realized in field. The heterosis in yield and its components of F1 hybrids and F2 was superior to the best and mean parent. Over dominance was notable in the agronomic and morphologic traits in F1 and F2 and vigor was noted in grain yield, biological yield, number of primary and in secondary branches. This study demonstrates that Chickpea hybridization in controlled conditions is successful (despite chickpea is autogamous species) and the results are showing high abilities for yield improvement for chickpea. The heterosis was evaluated and was highest in crosses involving parents more genetically dissimilar as for Desi x Kabuli progenies that expressed more heterosis in ND1 and B1D2 than for Kabuli x Kabuli in NK1 and B1K2. The results obtained suggested besides that the genes controlling yield are under additive and dominant inheritance. This work allows the selection of Chickpea high yielding genotypes at early generation (in F1 and F2) of this breeding program and compares the heterosis and the improvements obtained in Desi x Kabuli and Kabuli x Kabuli crosses.
\end{abstract}

Keywords: Heterosis; Gain in Yield; Gain in Branches; Additive Genes; Stability; Selection

\section{Introduction}

Approximately 6.5 billion people currently live on our planet, and by 2050 , that number is projected to rise by almost $50 \%$ to over 9 billion. We will be increasingly faced with the demand to produce more food for more people with fewer resources, and we will need to draw more heavily on high quality crops to provide for this growing demand. Chickpea has a head start in this agricultural race. Chickpea is a good source of energy, protein, minerals, vitamins, fibre, and also contains potentially healthbeneficial phytochemicals [1]. The Chickpea is playing a leading role in food safety in the world by covering the deficit in proteins of daily food ration of Indian and African Sub Sahara populations. The designed chickpea based infant follow-on formula meets the WHO/FAO requirements on complementary foods and also the EU regulations on follow-on formula with minimal addition of oils, minerals and vitamins. It uses chickpea as a common source of carbohydrate and protein hence making it more economical and affordable for the developing countries without compromising the nutrition quality [2].

Opportunities in the major cropping regions depend on both reducing the crop risk and improving productivity [3].

However, amongst pulse crops chickpea has consistently maintained a much more significant status, ranking second in area (15.3\% of total) and third in production (14.6\%).

This culture occupies the third row in term of production (14.6\%) and the second in surface (15.3\%) among food legumes in the world [4]. Chickpea is cultivated mostly in the Mediterranean basin, the Near East, Central and South Asia, East Africa, South America, North America and, more recently, in Australia. The main producers are India, Australia and Pakistan, contributing $67.32 \%, 6.19 \%$ and $5.72 \%$, respectively, to global production [5]. 
Not only is chickpea an important source of protein in human diets, but it also plays a significant role in maintaining soil fertility, particularly in dry lands by fixing atmospheric nitrogen $(\mathrm{N})$. Of particular relevance to the overall grain yield responses is the contribution of chickpea to soil $\mathrm{N}$ status through its ability to fix atmospheric $\mathrm{N}$ and effects on root pathogens of antecedent crops, thus improving the $\mathrm{N}$ nutrition and yield of subsequent cereals by as much as $70 \%$ [6,7]. Like any other legume, the productivity of chickpea is generally low with the average yields ranging from 570 to $766 \mathrm{~kg} / \mathrm{ha}$ in Asia, $600-660 \mathrm{~kg} / \mathrm{ha}$ in Africa, $1600 \mathrm{~kg} / \mathrm{ha}$ in North and Central America and average $750 \mathrm{~kg} / \mathrm{ha}$ in Europe [8]. These figures underline the need for genetic enhancement of productivity and achieving greater stability in chickpea.

Agronomical practices for the improvement of yield in chickpea are not efficient because yield is a complex character that highly depends on the environment. Indeed, all 30 publications report highly significant $\mathrm{G} \times \mathrm{E}$ interaction for yield, which suggests that the issue is important in chickpea [9]. Researchers in this field noted that the progress is more important into simple hybrids selection such as [10].

Chickpea is a predominantly self-pollinated crop [11]. There are two distinct types of cultivated chickpea: Desi and Kabuli. The Desi types have pink flowers anthocyanin pigmentation on stems, and a colored and thick seed coat. The Kabuli types have white flowers, lack anthocyanin pigmentation on stems and have white or beige-colored seeds with a ram's head shape, a thin seed coat and a smooth seed surface [12].

Higher and more stable yields are the major goals of this chickpea-breeding programme, Which achieves by controlled hybridization chickpea improvement and analyses the heterosis of F1 hybrids and F2 segregating populations deriving from Desi x Kabuli and Kabuli x Kabuli crosses.

\section{Materials and Methods}

\section{Cultural Season of 2014-2015}

The genetic material used in this study is originated of ICARDA and was constituted of six parental cultivars; two Tunisian varieties Nour and Béjal agronomically high adapted to the Tunisian environment and four exotic landraces (two of Desi type originating from Pakistan and two Kabuli from Georgie) which are high yielding genotypes. This collection was sown on five dates during the season of 2014-2015 in the experimental station of INAT. A normal plant growth was noted for all the trial and hybridization was carried out under controlled conditions.

The crosses were initiated in field at the blooming stage (the parents of each cross were chosen as they shown complementarity in morphologic and agronomic traits).

$\begin{array}{ll}\text { Cultivar: } & \text { Coding: } \\ \text { Nour } & \mathrm{N} \\ \text { Béja1 } & \mathrm{B} 1 \\ \text { Dési1 } & \mathrm{D} 1 \\ \text { Dési2 } & \mathrm{D} 2 \\ \text { Kabuli1 } & \mathrm{K} 1 \\ \text { Kabuli2 } & \mathrm{K} 2 \\ \text { Nour x Desi1 } & \mathrm{H} 1=\mathrm{ND} 1 \\ \text { Nour x Kabuli1 } & \mathrm{H} 2=\mathrm{NK} 1 \\ \text { Béja1 x Dési2 } & \mathrm{H} 3=\mathrm{B} 1 \mathrm{D} 2 \\ \text { Béja1 x Kabuli2 } & \mathrm{H} 4=\mathrm{B} 1 \mathrm{~K} 2\end{array}$

The trial was conducted in field under normal conditions and supplemented by two irrigations in April-May of the dry spring. F1plants of all the crosses showed a vigor superior to both of $\mathrm{t}$ best and mean parents. We noted that hybrids stemming from Desi $\mathrm{x}$ Kabuli crosses showed much more important vigor which was characterized by a fast development of plants, with big size and widths of stems, leaves, sepals and flowers exceeding those of best parent. The rate of heterosis was important in F1 for all hybrid plants. We noted besides an erect bearing for all plants (excepted for hybrids of B1K2 which were semi erect). The plants were harvested at the end of their maturity (June 2015). The grains F1 were collected from the crosses and stored at $4^{\circ} \mathrm{C}$ for the next growing season.

\section{Cultural season of 2015-2016}

The hybrid (seeds) F1 obtained from crosses were seeded in the cultural season 2015-2016 in the experimental land of the INAT (TUNISAIN AGRONOMICAL NATIONAL INSTITUTE) on four dates (from December to end January). Fifteen seeds of every hybrid and parent cultivar were seeded in a line of two meters long. The trial was conducted under normal conditions without fertilizer nor pesticides contribution. Hand weeding and two supplementary irrigations in March and April were given during the training stage of pods (which is sensitive to dryness). The harvest of the plants F1 and the parents was conducted in mid-June at the end of the cycle of plant physiological maturity. We counted and noted the number of pods per plant and the number of grains per 
plant for ten plants at random of every hybrid (F1) and parent cultivar. Table 1 contains the means of number of pods and grains F2 per plant obtained by using MEAN PROCEDURE in SPSS STATISTICS 2.3 software.

\section{Growing season of 2016-2017}

A trial was conducted under rain-fed conditions in Béja (which is part of the sub wet Tunisian floor) at the season of culture 20162017 to obtain the plants F2 from the hybrids F1 of the previous season 2014-2015.

The grains F2 stemming of the harvest of 2016 and the grains of the parental cultivars were seeded on lines of 25 seeds and 2,5meters long. Two lines were separated by $50 \mathrm{~cm}$ and each plot contained two lines (50 seeds).

All the parental and segregating material showed fast development in rain fed field conditions demonstrating high adaptability especially in B1D2, B1K2 and ND1 and less for NK1 which the rate of levying and development were weaker. This result indicates that adaptation is under recessive control of genes. The harvest of the plants F2 and the parents was conducted at the end of plant physiological maturity (yield and its components were counted at the stage of maturity of plants and noted on ten plants F2 and parental cultivar in random (number of pods and grains F3 per plant). The means in Table 2, were obtained by using SPSS software version 2.3 with MEAN PROCEDURE.

The number of primary and secondary branches were also counted on ten plants and their means obtained by using SPSS software version 2.3 with MEAN PROCEDURE (Table 3 and 4).

The weight of vegetative matter of F2 and parents cultivar were obtained by weighing 20 dry plants without seeds; and the means obtained by SPSS procedure are included in Table 4.

\section{Results and Discussion}

\section{Heterosis in yield}

Season of culture 2015-2016 (F1 Plants): Cropping Season 2015-2016 (F1 Plants). Means of Number of pods per plant (NGP), mean of Number of grains per plant (NgrP), Genetic gain with respect to the best parent and Genetic gain with respect to parents mean respectively for the number of pods per plant (Gengain NGP/best parent; Gengain NGP/Parents mean) and the number of grains per plant (Gengain NgrP/best parent, Gengain NgrP/Parents mean). The data noted on the plants of the trial during the cropping season 2016-2017 and contained in Table1 showed that The hybrids F1 expressed high value of positive heterosis for all types of crosses and showed a big rate of improvement in yield and agronomical components so the hybrids accumulated largest number of dominant genes of adaptation to varied conditions (in the number of pods by plant and the number of seeds by plant) (Table 1).

The values of rate of gains varied from $113 \%$ to $188 \%$ (for the number of grains per plant). The upper values registered in ND1and B1D2 were 179\% and 149\% respectively), thus indicating the presence of over dominance control in the inheritance of yield particularly in Desi x Kabuli crosses. The Table 1 shows that Desi x Kabuli crosses expressed upper heterosis than Kabuli x Kabuli for the components of yield with regard to both best parent and parents mean (the gain of yield achieved 188\% while the upper value registered in Kabuli x Kabuli crosses was 137\%).

We also noted that the plants F1 of ND1 reached upper gain (172\% and 160\%) respectively for the number of pods by plant and the number of seeds by plant; and that B1D2 was under these values by expressing the rate of $132 \%$ and $125 \%$ respectively for the number of pods by plant and the number of seeds by plants. The gap between the values of heterosis in Desi x Kabuli crosses (between ND1 and B1D2) are correlated to the gap of dissimilarities in precocity, height and bearing of plant of the parental cultivars involved in the crosses ND1 and B1D2. We actually noted bigger dissimilarities in Nour and Desi1 than in Béja1 and Desi2. These results suggested besides that the control of genes of productivity and yields are checked by additive dominant genes and that the rate of dissimilarities between the parents involved in the crosses are determinant in hybrids for the gain rate.

Concerning Kabuli x Kabuli crosses the heterosis expressed showed that B1K2 was superior to NK1 in the number of pods by plant and in the number of seeds by plant with regard to best parent while NK1 was upper to B1K2 in the gain of number of seeds by plant with regard to the mean of parents.

We besides noted that Nour variety had better ability of recombination in Desi x Kabuli crosses (ND1) than Béja1 (B1D2) so the mother genotype have a major impact on the properties of hybrids, genes flow and the stability of the progenies.

Despite chickpea is autogamous this species showed big potentialities in improvement by expressing a big rate of heterosis (we measured high value of gain in yield and its components in Table 1). These results show that simple hybrids allow to reconcile stability, homogeneity and productivity by their homeostase due to heterosis.

The results of our study confirm the reports of concerning hybrid selection in crop plants [9]. 


\begin{tabular}{|c|c|c|c|c|c|c|}
\hline $\begin{array}{c}\text { Parents Landraces } \\
\text { and Hybrids }\end{array}$ & $\begin{array}{c}\text { Mean } \\
\text { NGP }\end{array}$ & $\begin{array}{c}\text { Gengain in NGP/ } \\
\text { best parent }\end{array}$ & $\begin{array}{c}\text { GengainNGP/ } \\
\text { Parents mean }\end{array}$ & $\begin{array}{c}\text { Mean } \\
\text { NgrP }\end{array}$ & $\begin{array}{c}\text { Gengain in NgrP/ } \\
\text { Bestparent }\end{array}$ & $\begin{array}{c}\text { Gengain in NgrP/ } \\
\text { Parents mean }\end{array}$ \\
\hline D1 $\left(\mathrm{P}_{1}\right)$ & 65 & & & 100 & & \\
\hline D2 $\left(\mathrm{P}^{2}\right)$ & 71 & & & 106 & & \\
\hline N $\left(\mathrm{P}^{3}\right)$ & 60 & & & 70 & & \\
\hline B1 $\left(\mathrm{P}_{4}\right)$ & 50 & & & 70 & & \\
\hline K1 $\left(\mathrm{P}^{5}\right)$ & 47 & & & 55 & & \\
\hline K2 $\left(\mathrm{P}^{6}\right)$ & 53 & & & 66 & & \\
\hline ND1 $\left(\mathrm{H}^{1}\right)$ & 112 & $172 \%$ & $179 \%$ & 160 & $160 \%$ & $188 \%$ \\
\hline NK1 $\left(\mathrm{H}_{2}\right)$ & 72 & $120 \%$ & $135 \%$ & 85 & $121 \%$ & $137 \%$ \\
\hline B1D2 $\left(\mathrm{H}_{3}\right)$ & 90 & $126 \%$ & $149 \%$ & 120 & $113 \%$ & $136 \%$ \\
\hline B1K2 $\left(\mathrm{H}_{4}\right)$ & 70 & $132 \%$ & $135 \%$ & 88 & $125 \%$ & $129 \%$ \\
\hline
\end{tabular}

$\mathrm{NG} / \mathrm{P}=$ number of pods per plant; $\mathrm{Ngr} / \mathrm{P}=$ number of grain per plant

Genetic Gain/ best parent $=(\mathrm{H}-\mathrm{P}) / \mathrm{P} \times 100 ; \mathrm{P}$ is the mean value of best parent for NGP and NgrP; $\mathrm{H}$ is the mean of the hybrid Genetic Gain/ Parents mean $=\left(\mathrm{H}-\mathrm{P}_{\mathrm{m}}\right) / \mathrm{P}_{\mathrm{m}} \times 100 ; \mathrm{Pm}$ is the mean of NGP and NgrP of the two crossed parents; $\mathrm{H}$ is the mean of the hybrid

Means value are obtained from the data noted on 10 plants in random for every cultivar and hybrid [13]

Table 1: Cropping Season 2015-2016 (F1 Plants). Means of Number of pods per plant (NGP), mean of Number of grains per plant (NgrP), Genetic gain with respect to the best parent and Genetic gain with respect to parents mean respectively for the number of pods per plant (Gengain NGP /best parent; Gengain NGP /Parents mean) and the number of grains per plant (Gengain NgrP/ best parent, Gengain NgrP /Parents mean)

Season of culture 2016-2017 (F2 Plants): Cropping Season 2016-2017 (F2 Plants). Means of Number of pods per plant (NGP), mean of Number of grains per plant (NgrP), Genetic gain with respect to the best parent and Genetic gain with respect to parents mean respectively for the number of pods per plant (Gengain NGP/best parent; Gengain NGP /Parents mean) and the number of grains per plant (Gengain NgrP/best parent, Gengain NgrP/Parents mean) (Table 2).

The data noted on the plants of the trial during the cropping season 2016-2017are contained in Table 2 and showed a positive expression of heterosis in Desi x kabuli as well as in Kabuli x Kabuli crosses excepted for NK1 which heterosis was negative. Besides we noted a depression of consanguinity with regard to the year 2015-2016 for ND1 (134\%/179\% respectively) and for NK1 too. We also noted the rate of gain in B1K2 (136\%) have reached the gain rate of ND1 (136\%).

Concerning B1D2 and B1K2 the expression of heterosis remained stable between 2015-2016 and 2016-2017; the gain in number of pods by plant of B1D2 was 126\%/130\% respectively for 2015-2016 and 2016-2017 and 132\%/136\% for B1K2.

The number of seeds per plant had undergone a weak depression of consanguinity (10\%) for B1D1 and B1K2 between the two cultural years (113/103\% and $125 / 116 \%$ respectively).

We observed also that NK1 segregating populations was less adapted and that depression of consanguinity was essentially observed in crosses involving Nour, while the crosses involving Béjal showed stability by the two growing seasons (2015-2016) and (20162017) ; the gain of yield remained stable between the two years: 130 and 136\% against 126 and 132\% respectively for B1D2 and B1K2.

The results of heterosis in (2016-2017) cropping season allowed the selection of B1D2 and B1K2 high yielding genotypes in F2.

For the crosses introduced on Nour the gain passed from 170/128\% to 133/82\% respectively for ND1 and NK1. So selecting genotypes for high number of pods by plant should be more efficient in further generations for ND1.

Concerning the number of seeds by plant a depression was carried out for all the crosses initiated ND1, NK1, B1D2 and B1K2 whose values of gains were respectively $160,121,113,125$ in the season of (2015-2016) and 114, 81, 103, 116 in (2016-2017).

The number of pods by plant was less stable during the two growing seasons excepted for B1K2 and B1D2 have the most adapted genotypes.

It emerges from the two Tables 1 and 2 that genetic gains in yield stemming from Kabuli x Kabuli crosses favored B1K2 which have high ability in adaptation than NK1while in Desi x Kabuli crosses higher heterosis was expressed but was less stable through the F2.

The stability of heterosis through segregating generations is possible but not evident suggesting the impact of parent genotypes and especially the mother genotype which are involved in determining the stability of the improved characters. 


\begin{tabular}{|c|c|c|c|c|c|c|}
\hline $\begin{array}{c}\text { Cultivars And } \\
\text { Hybrids }\end{array}$ & $\begin{array}{c}\text { Mean } \\
\text { NG/P }\end{array}$ & $\begin{array}{c}\text { Gengain NGP/ } \\
\text { best Parent }\end{array}$ & $\begin{array}{c}\text { Gengain NGP/ } \\
\text { Parents mean }\end{array}$ & $\begin{array}{c}\text { Mean } \\
\text { NgrP }\end{array}$ & $\begin{array}{c}\text { Gengain NgrP/ } \\
\text { best parent }\end{array}$ & $\begin{array}{c}\text { Gengain NgrP/ } \\
\text { Parents mean }\end{array}$ \\
\hline D1 & 71 & & & 108 & & \\
\hline D2 & 79 & & & 116 & & \\
\hline N & 61 & & & 70 & & \\
\hline B1 & 80 & & & 95 & & \\
\hline K1 & 67 & & & 65 & & \\
\hline K2 & 68 & & & 96 & & \\
\hline ND1 & 89 & $134 \%$ & $135 \%$ & 123 & $114 \%$ & $139 \%$ \\
\hline NK1 & 53 & $79 \%$ & $83 \%$ & 56 & $81 \%$ & $84 \%$ \\
\hline B1D2 & 104 & $130 \%$ & $132 \%$ & 120 & $103 \%$ & $118 \%$ \\
\hline B1K2 & 109 & $136 \%$ & $147 \%$ & 112 & $116 \%$ & $118 \%$ \\
\hline
\end{tabular}

$\mathrm{NG} / \mathrm{P}=$ number of pods per plant; Ngr/P = number of grain per plant

Genetic Gain/best parent $=(\mathrm{H}-\mathrm{P}) / \mathrm{P} \times 100 ; \mathrm{P}$ is the mean value of best parent for NGP and NgrP; $\mathrm{H}$ is the mean of the hybrid

Genetic Gain/Parents mean $=\left(\mathrm{H}-\mathrm{P}_{\mathrm{m}}\right) / \mathrm{P}_{\mathrm{m}} \mathrm{x} 100 ; \mathrm{Pm}$ is the mean of NGP and NgrP of the two crossed parents; $\mathrm{H}$ is the mean of the hybrid Means values are obtained from the data noted on 10 plants in random for every cultivar and hybrid [14]

Table 2: Cropping Season 2016-2017 (F2 Plants). Means of Number of pods per plant (NGP), mean of Number of grains per plant (NgrP), Genetic gain with respect to the best parent and Genetic gain with respect to parents mean respectively for the number of pods per plant (Gengain NGP/best parent; Gengain NGP/Parents mean) and the number of grains per plant (Gengain NgrP/best parent, Gengain NgrP/ Parents mean)

\section{Heterosis of Agro- Morphological characters}

Gain in primary and secondary branches: Cropping season 2016-2017 (F2 plants). Means of The number of Primary and secondary branches, Genetic Gain in primary and secondary branches with respect to the best parent and with respect to parents (Table 3).

According to table3 the values of heterosis in F2 registered for the primary and secondary branches are the highest in Desi $\mathrm{x}$ kabuli crosses and we noted a maximum of gain for ND1 (218\%). For B1D2 a rate of 157\% for the primary branches was registered and we noted $126 \% / 134 \%$ for ND1, B1D2 respectively for secondary branches.

So primary branches are controlled by dominant additives genes for the crosses involving Desi and Kabuli parents and we noted epistasic effects (highly visible in NK1) also involved in the control of Kabuli x Kabuli crosses.

For secondary branches epistasic effects were increasingly controlling the genes (this was due to a shorter distance between the parents of Kabuli type than for Desi/Kabuli parents) so that genetic regulatory sequences were active in the hybrids derived from Kabuli parents.

The results included in table 3 showed that all the hybrids obtained from Béja1 were superior to the best parent whereas only ND1 was superior for Nour.

Because the branches are the support of pods and from the values of heterosis expressed in the number of branches (table3) there is evidence of great potentialities in gain of yield by this controlled hybridization

\begin{tabular}{|cc|c|c|}
\hline $\begin{array}{c}\text { Parents Cultivars }(\mathbf{P n}) \\
\text { Hybrids }(\mathbf{H n})\end{array}$ & Wvm $(\mathbf{g})$ & $\begin{array}{c}\text { Gengain of Wvm/ best } \\
\text { parent }\end{array}$ \\
\hline $\mathrm{D} 1$ & $\left(\mathrm{P}_{1}\right)$ & 175 & \\
\hline $\mathrm{D} 2$ & $\left(\mathrm{P}_{2}\right)$ & 213 & \\
\hline $\mathrm{N}$ & $\left(\mathrm{P}_{3}\right)$ & 548 & \\
\hline $\mathrm{B} 1$ & $\left(\mathrm{P}_{4}\right)$ & 596 & \\
\hline $\mathrm{K} 1$ & $\left(\mathrm{P}_{5}\right)$ & 641 & \\
\hline $\mathrm{K} 2$ & $\left(\mathrm{P}_{6}\right)$ & 518 & \\
\hline $\mathrm{ND} 1$ & $\left(\mathrm{H}_{1}\right)$ & 613 & $112 \%$ \\
\hline $\mathrm{NK} 1$ & $\left(\mathrm{H}_{2}\right)$ & $243(6$ plants $)$ & $126 \%$ \\
\hline B1D2 & $\left(\mathrm{H}_{3}\right)$ & 749 & $125 \%$ \\
\hline B1K2 & $\left(\mathrm{H}_{4}\right)$ & 874 & $146 \%$ \\
\hline
\end{tabular}

Mean RAM1: mean of the number of primary branches per plant noted on 10 plants in random (during 2016-2017 growing season);

Mean RAM2: mean of the number of secondary branches per plant noted on 10 plants in random (during 2016-2017) [14]

Table 3: Cropping season 2016-2017 (F2 plants). Means of The number of Primary and secondary branches, Genetic Gain in primary and secondary branches with respect to the best parent and with respect to parents mean 
Gain in Pecto-cellulosic matter: Cropping Season 2016-2017 (F2 Plants).Weight (without seeds) of twenty plants of parent cultivars and F2 of every cross (Table 4).

According to table 4 Kabuli x Kabuli crosses gave better progress in vegetative matter and growth (126\%and 146\%) against (112 and $125 \%$ ) of Desi x Kabuli crosses.

B1K2 registered (146\%) as a genetic gain (with regard to the best parent) for the weight of pectocellulosic matter. This value of gain for B1K2 is superior to all the values obtained for the crosses ND1, BID2 and NK1 (112\%, 125\% and 126\%) moreover B1K2 corresponds to cross of which yield heterosis was very stable through F1 and F2.

These results suggest dominant and additive control of the genes of biomass and plant architecture.

\begin{tabular}{|c|c|c|c|c|c|c|}
\hline $\begin{array}{c}\text { Cultivars And } \\
\text { Hybrids }\end{array}$ & $\begin{array}{c}\text { Mean } \\
\text { RAM1 }\end{array}$ & $\begin{array}{c}\text { Gengain RAM1/ } \\
\text { best parent }\end{array}$ & $\begin{array}{c}\text { GengainRAM1/ } \\
\text { parents mean }\end{array}$ & $\begin{array}{c}\text { Mean } \\
\text { RAM2 }\end{array}$ & $\begin{array}{c}\text { Gengain } \\
\text { RAM2/best parent }\end{array}$ & $\begin{array}{c}\text { Gengain RAM2/ } \\
\text { parents mean }\end{array}$ \\
\hline D1 & 3,4 & & & 14,7 & & \\
\hline D2 & 2,9 & & & 20,9 & & \\
\hline N & 3 & & & 25 & & \\
\hline B1 & 5,1 & & & 24,6 & & \\
\hline K1 & 5,6 & & 40 & & \\
\hline K2 & 6,5 & & & 30 & & $126 \%$ \\
\hline ND1 & 7 & $205 \%$ & $218 \%$ & 25 & $100 \%$ & $77 \%$ \\
\hline NK1 & 3 & $53 \%$ & $70 \%$ & 25 & $63 \%$ & $134 \%$ \\
\hline B1D2 & 6,3 & $123 \%$ & $157 \%$ & 30,6 & $124 \%$ & $113 \%$ \\
\hline B1K2 & 7,2 & $111 \%$ & $124 \%$ & 30,9 & $103 \%$ & \\
\hline
\end{tabular}

Wvm =Weight of Vegetative Matter of 20 plants; excepted for NK1 which was noted for 6 plants Gengain/best parent $=(\mathrm{H}-\mathrm{P}) \mathrm{x}$ 100/H; $\mathrm{H}$ is obtained by weighing 20 plants every hybrid and $\mathrm{P}$ is the weight of 20 plants of the best parent involved in the considered cross [14]

Table 4: Cropping season 2016-2017 (F2 plants). Means of Weight of vegetative matter (Wvm) and Genetic Gain in pecto-cellulosic matter (plants without grains) with respect to the best parent (Gengain/best parent)

\section{Conclusion}

By this breeding program we have achieved the improvement of agronomical characters, and yield grain in chickpea in two ways by Desi x Kabuli and Kabuli x Kabuli crosses between complementary parents. It emerges also that the hybrids with higher rate of heterosis are ND1 for Desi x Kabuli crosses and B1K2 for the Kabuli x Kabuli. The selection of high yielding and stable genotypes is possible in early generation F1 and F2 for B1K2 and B1D1 while further generations are necessarily for the selection of ND1.

While all the crosses expressed high rates of heterosis in yield, pods, branches and vegetative matter in the descendants, the stability in yield and its components through the generations was present only in the crosses involving Béja1(B1K2 and B1D1. We deduct that the heterosis level and the stability are mainly influenced by the parent genotypes and not by cross type. It is likely that certain necessary regulations in the action of genes in the hybrid are active depending on mother genotype, and that some epigenetic factors control the stability in progenies.

Hybridization in chickpea offers many advantages as the creation of new varietal types highly productive, the modulation by the heterozygous state of unusable genes in the homozygous state and the accumulation of dominant genes to the improvement of nutritional quality in early generations of the breeding program.

\section{References}

1. Wood JA, Grusak MA (2006) Nutritional Value of Chickpea Chickpea Breeding and Managements 5: 101 CAB International.

2. Malunga LN, Shimrit Bar-El DS, Zinal E, Berkovich Z, Abbo S, et al. (2014) The potential use of chickpeas in development of infant follow-on formula. Nutr J 13: 8 .

3. Redden And Berger (2007) Chickpea Breeding and Managements P25 CAB International.

4. FAO (2006).

5. FAOSTAT. Food and Agriculture Data.

6. Felton W, Marcellos H, Martin RJ (1995) A comparison of three fallow management strategies for the long term productivity of wheat in northern New South Wales. Aus J Experi Agri 35: 915-21.

7. Aslam M, Mahmood IA, Peoples MB, Schwenke GD, Herridge DF (2003) Contribution of chickpea nitrogen fixation to increased wheat production and soil organic fertility in rainfed cropping. Biology and Fertility of Soils 38: 59-64.

8. Smithson JB, Lenné JM (1996) Varietal mixtures: a viable strategy for sustainable productivity in subsistence agriculture. Ann Appl Biol 128: 127-58.

9. Berger JD, JS Speigjers, RL Sapra, UC Sood (2006) Genotype by environment interaction and chickpea improvement In Chickpea breeding 30: 617 CAB International. 
10. Gallais A (2009) Hétérosis et variétés hybrides en amélioration des plantes. Editions Quae.

11. Singh KB (1987) Chickpea breeding In: Saxena MC, Singh KB The Chickpea. CAB International, Wallingford, UK, pp 409.

12. Jukanti AK, Gaur PM, Gowda CLL, Chibbar RN (2012) Nutritional quality and health benefits of chickpea (Cicer arietinum L.): A review. Br J Nutr 108: S11-26. 13. Bayahi K, Rezgui S (2015) Agro-Morphological Characterization and Genetic Study of New Improved Lines and Cultivars of Chickpea (Cicer Arietinum L.). J Plant Breed Genet 3: 59-65.

14. Bayahi K, Rezgui S (2016) Genetic Study of Nutritional and Physicochemical Characters of Chickpea Lines and Cultivars (Cicer arietinum L.). J Agri Sci 9: 151-9. 